\title{
Upregulation of Connexin 30 in Intestinal Phenotype Gastric Cancer and Its Reduction during Tumor Progression
}

\author{
Kazuhiro Sentani ${ }^{\mathrm{a}}$ Naohide Oue $^{\mathrm{a}}$ Naoya Sakamoto $^{\mathrm{a}}$ Katsuhiro Anami $^{\mathrm{a}}$ \\ Yutaka Naito $^{\text {a }}$ Kazuhiko Aoyagi $^{\mathrm{b}}$ Hiroki Sasaki ${ }^{\mathrm{b}}$ Wataru Yasui $^{\mathrm{a}}$ \\ a Department of Molecular Pathology, Hiroshima University Graduate School of Biomedical Sciences, Hiroshima, \\ and ${ }^{\mathrm{b}}$ Genetics Division, National Cancer Center Research Institute, Tokyo, Japan
}

\section{Key Words}

Gastric cancer • Intestinal phenotype • Connexin 30 •

Microarray

\begin{abstract}
Aims: The mucin phenotype is associated with clinicopathological findings and tumorigenesis in gastric cancer (GC). The aim was to search for a novel marker regulating the intestinal phenotype of GC. Methods and Results: We performed microarray analyses, and GJB6 (encoding connexin 30) was identified as a gene associated with the intestinal phenotype. Immunostaining of connexin 30 in 169 GC cases revealed that $47(28 \%)$ cases were positive for connexin 30 , while connexin 30 was negative in nonneoplastic gastric tissue. Connexin 30-negative GC cases showed more advanced T grade, $\mathrm{N}$ grade, and tumor stage than connexin 30-positive GC cases. Six (13\%) GC cases positive for connexin 30 were histologically of the differentiated type. In addition, the expression of gastric and intestinal phenotypes of GC was examined by immunostaining for MUC5AC, MUC6, MUC2, and CD10. Connexin 30 expression occurred more frequently in the intestinal phenotype (48\%) than in other phenotypes (21\%) of GC. Conclusion: These results indicate that the expression of connexin 30 is a novel differentiation marker mediating the biological behavior of intestinal phenotype GC.
\end{abstract}

Copyright $\odot 2010$ S. Karger AG, Basel

\section{Introduction}

According to the World Health Organization, gastric cancer (GC) is the fourth most common malignancy worldwide, with approximately 870,000 new cases occurring yearly. Mortality due to GC is second only to that due to lung cancer [1]. Cancer develops as a result of multiple genetic and epigenetic alterations [2,3]. Better knowledge of the changes in gene expression that occur during gastric carcinogenesis may lead to improvements in diagnosis, treatment, and prevention. Identification of novel biomarkers for cancer diagnosis and novel targets for treatment are major goals in this field [4]. Array-based hybridization [5] and serial analysis of gene expression (SAGE) [6] are currently the most common approaches used to identify potential molecular markers for cancer.

GCs have been classified into 2 histological types: an intestinal type and a diffuse type by Lauren [7], or a differentiated type and an undifferentiated type by Nakamura et al. [8], based on the tendency toward gland formation. It has been suggested that these 2 types involve distinct pathways during carcinogenesis [7-10]. Recent studies have demonstrated that GCs are also classified as having a gastric, gastric and intestinal mixed, or intestinal phenotype depending on the expression of mucin phenotypic markers [11-18]. The mucin expression and phenotype of tumors are associated with clinicopatho-

\section{KARGER}

Fax +4161306 1234 E-Mail karger@karger.ch www.karger.com
Wataru Yasui, $\mathrm{MD}, \mathrm{PhD}$

Department of Molecular Pathology

Hiroshima University Graduate School of Biomedical Sciences

1-2-3 Kasumi, Minami-ku, Hiroshima 734-8551 (Japan)

Tel. +81 82257 5145, Fax +81 82257 5149, E-Mail wyasui@ hiroshima-u.ac.jp 
logical findings and tumorigenesis in GCs. However, the clinical importance of intestinal mucin in GCs is still controversial and no definite conclusions have been reached [12-18]. Candidate genes controlling gastric and intestinal phenotypes include several transcription factors [19]. The caudal-related homeobox 2 gene (CDX2) is an intestine-specific transcription factor that is expressed in nonneoplastic mucosa from the duodenum to the distal colon and is detected in GC with the intestinal phenotype [20]. SOX2, an Sry-like high-mobility group box gastric transcription factor, is expressed in normal gastric mucosa and GC with the gastric phenotype [21]. By performing microarray analyses, we recently discovered that the expression of connexin 30 was observed in intestinal phenotype GC.

Connexins, a family of 20 transmembrane proteins in humans, comprise the main subunits of gap junctions, which are specialized clusters of intercellular channels that allow adjacent cells to directly share ions and hydrophilic molecules of up to $1 \mathrm{kDa}$ in size [22]. Gap junctional intercellular communication (GJIC) is thought to control tissue homeostasis and to coordinate cellular processes such as proliferation, migration, and differentiation $[23,24]$. Neoplastic transformation is frequently associated with a loss of GJIC and with a reduced expression of connexins in various tumors $[25,26]$. The forced expression of connexins in connexin-deficient cell lines results in the inhibition of tumor growth and the induction of apoptosis in vitro as well as the prevention of tumor formation in vivo $[27,28]$. On the other hand, accumulating evidence indicates that connexin 26 , a connexin family member, is overexpressed in carcinomas including those of the head and neck, colon, and pancreas [29-32]. Increased connexin 26 expression has been observed in invasive breast carcinomas and metastatic lymph nodes $[33,34]$. Together, these strands of evidence appear to contradict the conventionally held view of the role of connexins as tumor suppressors. The localization of connexin 30 has been observed in normal skin [35], cochlea [36] and brain [37]. Connexin 30 gene mutations cause dominant nonsyndromic hearing loss $[38,39]$, and they have been identified in Clouston syndrome (hidrotic ectodermal dysplasia) [40]. Little is known about the role of connexin 30 in human neoplasia. While the expression of connexin 30 is decreased in human head and neck cancer [41] and in cervical dysplasia of the uterus [42], connexin 30 is upregulated in human skin tumors [43]. Thus, the exact pathogenic mechanisms associated with connexin 30 in carcinogenesis remain obscure.
The present study represents the first detailed analysis of connexin 30 expression in GC. To clarify the pattern of expression and localization of connexin 30 in GC, we performed immunohistochemical analysis of surgically resected GC samples. In addition, we investigated the association between connexin 30 and various markers determining the gastric/intestinal phenotypes (MUC5AC, MUC6, MUC2, and CD10).

\section{Materials and Methods}

\section{Tissue Samples}

Primary tumor samples and the corresponding nonneoplastic gastric mucosa were collected from 169 patients with GC (123 men and 46 women; age range $29-88$ years; mean 70 years). $\mathrm{Pa}-$ tients were treated at Hiroshima University Hospital or affiliated hospitals. For RNA extraction, tissue samples obtained at the time of surgery were immediately embedded in OCT compound (Sakura Finetechnical Co., Ltd., Tokyo, Japan), frozen in liquid nitrogen, and stored at $-80^{\circ} \mathrm{C}$. For quantitative reverse transcription-polymerase chain reaction (RT-PCR) analysis, 18 GC samples and the corresponding nonneoplastic mucosa samples were used. The samples were obtained during surgery at Hiroshima University Hospital. We confirmed microscopically that the tumor specimens were predominantly $(>50 \%)$ cancer tissue. Samples were frozen immediately in liquid nitrogen and stored at $-80^{\circ} \mathrm{C}$ until used. Samples of normal brain, spinal cord, heart, skeletal muscle, lung, stomach, small intestine, colon, liver, pancreas, kidney, uterus, bone marrow, spleen, peripheral leukocytes, and trachea were purchased from Clontech (Palo Alto, Calif., USA). For immunohistochemical analysis we used archival formalin-fixed paraffin-embedded tissues from 169 patients who had undergone surgical excision for GC. The 169 GC cases were histologically classified as 102 of the differentiated type and 67 of the undifferentiated type, according to the Japanese Classification of Gastric Carcinomas [44]. Tumor staging was carried out according to the TNM classification [45]. Because written informed consent was not obtained, identifying information for all samples was removed before analysis for strict privacy protection. This procedure was in accordance with the Ethical Guidelines for Human Genome/Gene Research enacted by the Japanese government.

\section{Quantitative RT-PCR}

Total RNA was extracted with an RNeasy Mini Kit (Qiagen, Valencia, Calif., USA), and $1 \mu \mathrm{g}$ of total RNA was converted to cDNA with a First Strand cDNA Synthesis Kit (Amersham Biosciences, Piscataway, N.J., USA). Quantitation of Connexin 30 mRNA levels in human tissue samples was done by real-time fluorescence detection as described previously [46]. Connexin 30 primer sequences were 5'-CAG TTG CCT TCT CTC CGA GG-3' and 5'CAT GGG ATG TTA CAC ACG CC-3'. PCR was performed with a SYBR Green PCR Core Reagents Kit (Applied Biosystems, Foster City, Calif., USA). Real-time detection of the emission intensity of SYBR Green bound to double-stranded DNA was performed with an ABI PRISM 7700 Sequence Detection System (Applied Biosystems) as described previously [47]. ACTB-specific 
Fig. 1. Quantitative RT-PCR analysis of connexin 30 in various human normal tissues and GC tissues. Clear connexin 30 expression is present in normal brain, spinal cord, bone marrow, uterus, etc. High levels of connexin 30 were observed in some GCs. The units are arbitrary and connexin 30 expression was calculated by the standardization of $1.0 \mu \mathrm{g}$ of total RNA from normal stomach as 1.0.

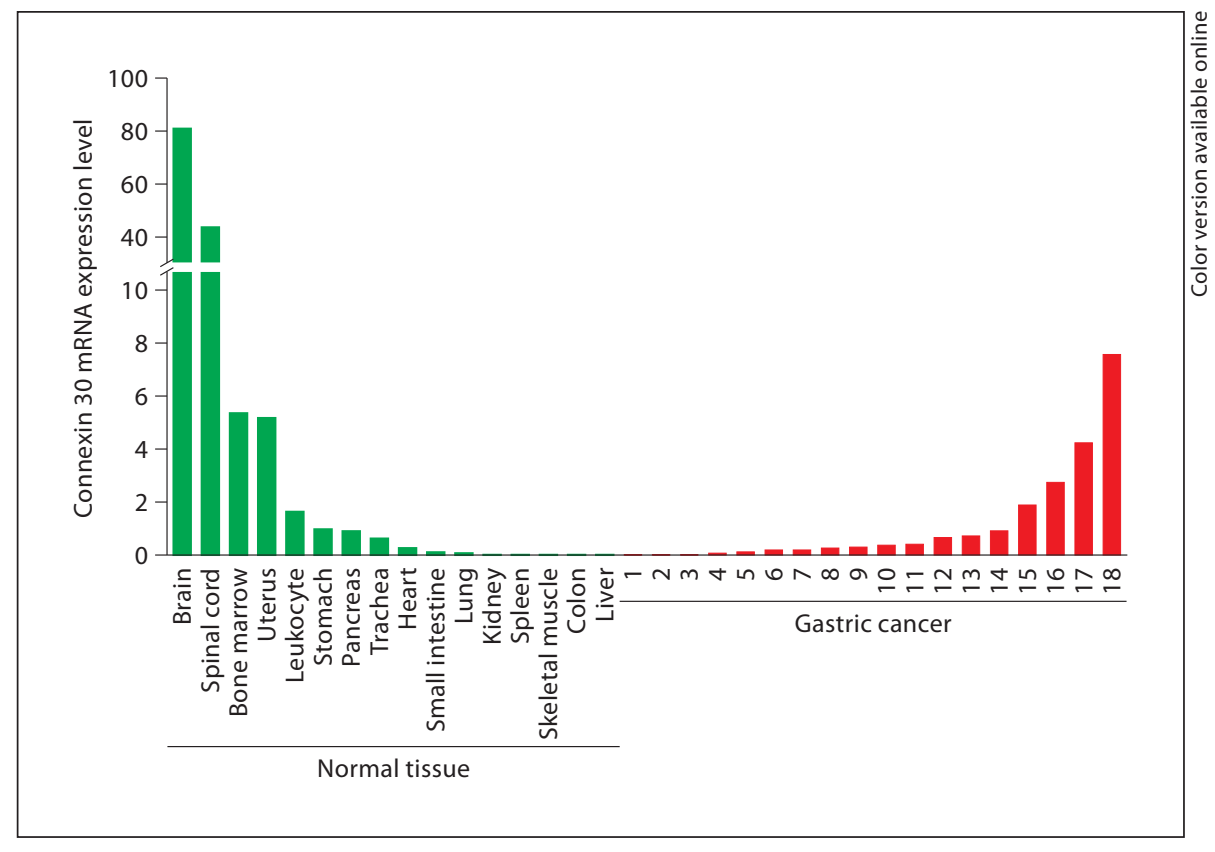

PCR products were amplified from the same RNA samples and served as internal controls.

\section{Antibodies}

Anti-connexin 30 antibody was purchased from Invitrogen/ Zymed Laboratories, Inc. (San Francisco, Calif., USA). We used 4 antibodies for analysis of the GC phenotypes: anti-MUC5AC (Novocastra, Newcastle, UK) as a marker of gastric foveolar epithelial cells, anti-MUC6 (Novocastra) as a marker of pyloric gland cells, anti-MUC2 (Novocastra) as a marker of goblet cells in the small intestine and colorectum, and anti-CD10 (Novocastra) as a marker of microvilli of absorptive cells in the small intestine and colorectum.

\section{Immunohistochemistry}

A Dako LSAB Kit (Dako, Carpinteria, Calif., USA) was used for immunohistochemical analysis. In brief, sections were pretreated by microwave treatment in citrate buffer for $15 \mathrm{~min}$ to retrieve antigenicity. After peroxidase activity was blocked with 3\% $\mathrm{H}_{2} \mathrm{O}_{2}$-methanol for $10 \mathrm{~min}$, sections were incubated with normal goat serum (Dako) for 20 min to block nonspecific antibody binding sites. Sections were incubated with the following primary antibodies: anti-connexin 30, anti-MUC5AC, anti-MUC6, antiMUC2, and anti-CD10 (all diluted 1:50). Sections were incubated with primary antibody for $1 \mathrm{~h}$ at $25^{\circ} \mathrm{C}$, followed by incubations with biotinylated mouse anti-rabbit IgG and peroxidase-labeled streptavidin for $10 \mathrm{~min}$ each. Staining was completed with a 10 min incubation with the substrate-chromogen solution. The sections were counterstained with $0.1 \%$ hematoxylin.

Connexin 30 staining was classified according to the percentage of stained cancer cells. Expression was considered to be 'negative' if $<10 \%$ of cancer cells were stained. When at least $10 \%$ of cancer cells were stained, the result of immunostaining was considered 'positive'.

Connexin 30 in Gastric Cancer
GC cases were classified into 4 phenotypes: gastric phenotype, intestinal phenotype, gastric and intestinal mixed phenotype, and unclassified phenotype. The criteria [20] for the classification of gastric phenotype and intestinal phenotype were as follows: GCs in which more than $10 \%$ of the cells displayed the gastric or intestinal epithelial cell phenotype were gastric phenotype or intestinal phenotype cancers, respectively; those sections that showed both gastric and intestinal phenotypes were classified as gastric and intestinal mixed phenotype, and those that lacked both the gastric and the intestinal phenotypes were classified as the unclassified phenotype.

Double Immunofluorescence Staining

Double immunofluorescence staining was performed as described previously [48]. Alexa Fluor 488-conjugated chicken antirabbit IgG and Alexa Fluor 546-conjugated goat anti-mouse IgG were used as secondary antibodies (Molecular Probes, Eugene, Oreg., USA).

Statistical Methods

Correlations between clinicopathologic parameters and connexin 30 staining were analyzed by Fisher's exact test. $p<0.05$ was considered statistically significant.

\section{Results}

\section{Expression of Connexin 30 in Systemic Normal Tissues and GC Tissues}

Quantitative RT-PCR was performed to investigate the specificity of connexin 30 expression in 16 normal organs. As shown in figure 1, connexin 30 expression was clearly 

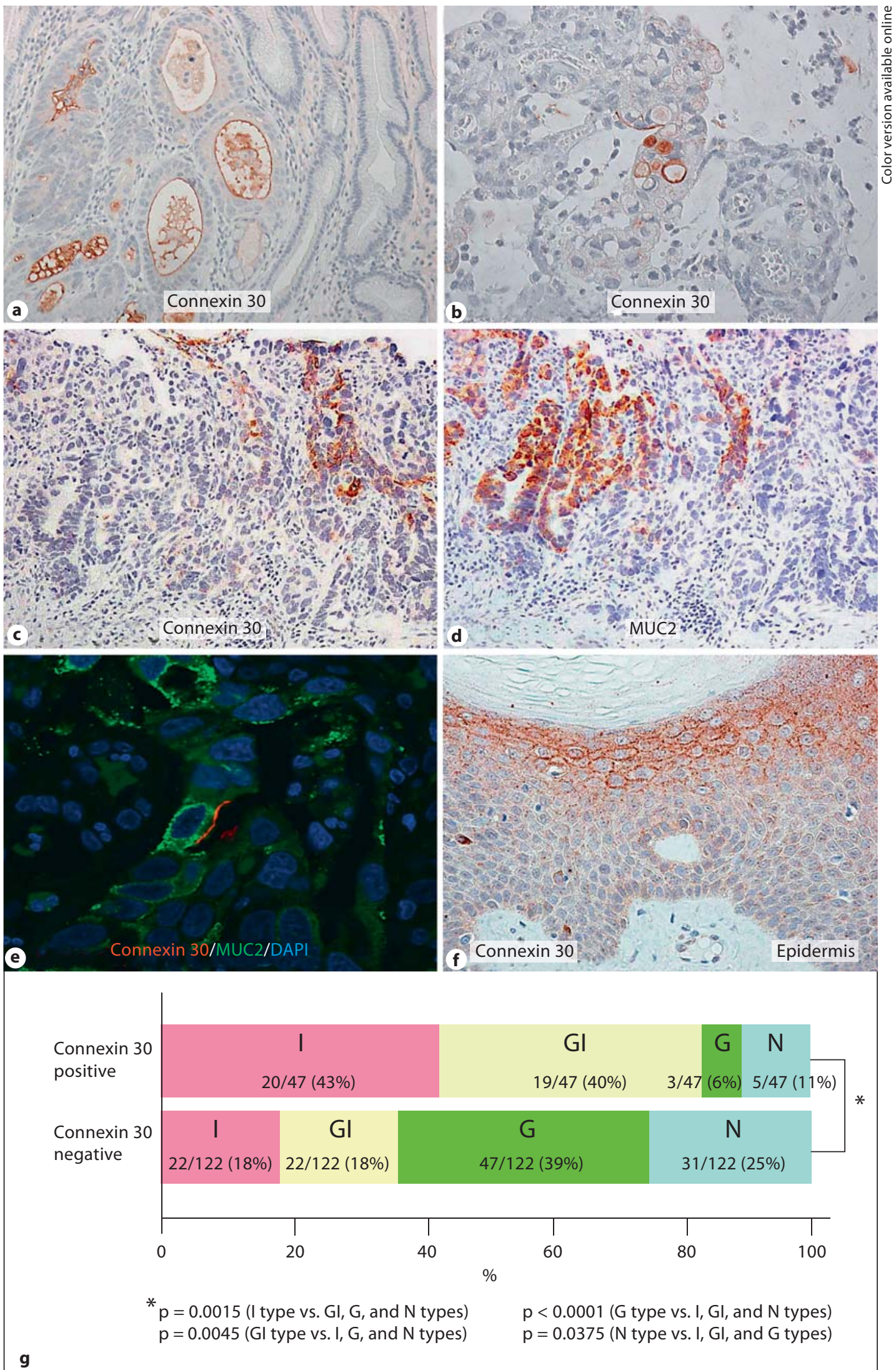

$\%$

$$
\begin{aligned}
& p<0.0001 \text { ( } G \text { type vs. I, Gl, and N types) } \\
& p=0.0375 \text { ( } N \text { type vs. I, Gl, and G types) }
\end{aligned}
$$


Table 1. Relationship between connexin 30 expression and clinicopathologic parameters in 169 GC cases

\begin{tabular}{|c|c|c|c|}
\hline & \multicolumn{2}{|c|}{$\begin{array}{l}\text { Connexin } 30 \\
\text { expression }\end{array}$} & \multirow[t]{2}{*}{$\begin{array}{l}\mathrm{p} \\
\text { value }\end{array}$} \\
\hline & $\begin{array}{l}\text { positive } \\
(\mathrm{n}=47)\end{array}$ & $\begin{array}{l}\text { negative } \\
(\mathrm{n}=122)\end{array}$ & \\
\hline \multicolumn{4}{|l|}{ Age } \\
\hline$\leq 65$ years $(n=46)$ & $13(28)$ & 33 & \multirow[t]{2}{*}{ NS } \\
\hline$>65$ years $(n=123)$ & $34(28)$ & 89 & \\
\hline \multicolumn{4}{|l|}{ Gender } \\
\hline Male $(\mathrm{n}=123)$ & $33(27)$ & 90 & \multirow[t]{2}{*}{ NS } \\
\hline Female $(\mathrm{n}=46)$ & $14(30)$ & 32 & \\
\hline \multicolumn{4}{|l|}{ Histology $^{1}$} \\
\hline Differentiated $(\mathrm{n}=102)$ & $41(40)$ & 61 & \multirow[t]{2}{*}{$<0.0001$} \\
\hline Undifferentiated $(n=67)$ & $6(9)$ & 61 & \\
\hline \multicolumn{4}{|l|}{ T grade } \\
\hline $\mathrm{T} 1(\mathrm{n}=83)$ & $35(42)$ & 48 & \multirow[t]{2}{*}{$<0.0001$} \\
\hline $\mathrm{T} 2 / \mathrm{T} 3 / \mathrm{T} 4(\mathrm{n}=86)$ & $12(14)$ & 74 & \\
\hline \multicolumn{4}{|l|}{$\mathrm{N}$ grade } \\
\hline No $(n=107)$ & $37(35)$ & 70 & \multirow[t]{2}{*}{0.0123} \\
\hline $\mathrm{N} 1 / \mathrm{N} 2 / \mathrm{N} 3(\mathrm{n}=62)$ & $10(16)$ & 52 & \\
\hline \multicolumn{4}{|l|}{$M$ grade } \\
\hline M0 $(\mathrm{n}=163)$ & $47(29)$ & 116 & \multirow[t]{2}{*}{ NS } \\
\hline M1 $(n=6)$ & $0(0)$ & 6 & \\
\hline \multicolumn{4}{|l|}{ Stage $^{2}$} \\
\hline Stage $0 / \mathrm{I}(\mathrm{n}=104)$ & $38(37)$ & 66 & \multirow[t]{2}{*}{0.0014} \\
\hline Stage II/III/IV $(\mathrm{n}=65)$ & $9(14)$ & 56 & \\
\hline
\end{tabular}

Figures in parentheses are percentages. p values were calculated by Fisher's exact test. NS = Not significant.

${ }^{1}$ Histology was classified according to the Japanese Classification of Gastric Carcinomas.

2 Tumor stage was classified according to International Union Against Cancer TNM classification of malignant tumors criteria.

Fig. 2. Immunohistochemical staining of connexin 30 and MUC2 in GC tissues (a-e). Connexin 30 was detected in the apical membranes of both well-differentiated GC (a) and poorly differentiated GC (b), but not in noncancerous epithelium. Serial sections showed that expression of connexin 30 (c) was partly adjacent to cytoplasmic expression of MUC2 (d). Double-immunostaining of connexin 30 (red) and MUC2 (green) revealed no colocalization of both molecules (e). Nuclei are stained with 4',6-diamidino-2phenylindole (DAPI; blue). Immunostaining of human epidermis as a positive control showed that connexin 30 was distributed in the keratinocytes of the upper spinous layers and the granular layers (f). Summary of connexin 30 expression and expression of the GC mucin phenotype (g). Expression of connexin 30 was observed more frequently in I-type and GI-type GC than in other (G and N) GC types. p values were statistically analyzed by Fisher's exact test. Colors refer to the online version only.

Connexin 30 in Gastric Cancer detected in the brain and the spinal cord and to a lesser extent in the bone marrow and uterus. However, the expression of connexin 30 was detected at low levels, or not at all, in other normal organs including the stomach. These results are consistent with those of a previous report [37]. Next, we analyzed quantitative RT-PCR in 18 GC samples. High levels of connexin 30 (tumor/normal ratio $>2$ ) were observed in 4 of the 18 GCs $(22 \%)$.

Immunohistochemical Analysis of Connexin 30 in GC

Quantitative RT-PCR revealed obvious connexin 30 expression in GC, although the levels were not very high. We therefore performed immunohistochemical analysis of connexin 30 in GC (fig. 2a-e). At first, we tested the specificity of the anti-connexin 30 antibody. Immunohistochemical analysis of normal skin tissue was performed, and connexin 30 was detected in the keratinocytes of the upper spinous layers and in those of the stratum granulosum (fig. 2f). This result was consistent with a previous report [49]. Using this antibody, we performed immunostaining of connexin 30 in 169 GCs and the corresponding nonneoplastic gastric mucosa. As a result, connexin 30 expression was detected in 47 of the 169 GCs $(28 \%)$ and was seen on the cell membrane, especially the apical membrane (fig. 2a, b). However, we sometimes observed its cytoplasmic accumulation (fig. 2c). There was no difference in connexin 30 expression levels between intratumor areas and infiltrative margins.

Connexin 30 was scarcely expressed in any corresponding nonneoplastic gastric mucosa or intestinal metaplasia. Next, we analyzed the relationship between connexin 30 expression and clinicopathologic characteristics. The expression of connexin 30 was observed more frequently in the differentiated type of GC than in the undifferentiated type $(\mathrm{p}<0.0001)$ (table 1$)$. Localized distribution of connexin 30-positive GC cells in tumors that had more than 1 histological component were also often observed in differentiated GC components rather than in undifferentiated components.

Furthermore, connexin 30 staining showed a significant inverse correlation with the depth of invasion $(\mathrm{p}<$ $0.0001)$, lymph node metastasis ( $p=0.0123)$, and TNM stage $(\mathrm{p}=0.0014)$. There was no significant association between connexin 30 staining and other parameters (age, gender, or M grade).

\section{Association between Connexin 30 Expression and Gastric/Intestinal Mucin Markers}

We next investigated the association between connexin 30 expression and various markers determining the 
Table 2. Relationship between connexin 30 expression and gastric/intestinal mucin markers in 169 GC cases

\begin{tabular}{|c|c|c|c|}
\hline & \multicolumn{2}{|c|}{ Connexin 30 expression } & \multirow[t]{2}{*}{$\mathrm{p}$ value } \\
\hline & $\begin{array}{l}\text { positive } \\
(\mathrm{n}=47)\end{array}$ & $\begin{array}{l}\text { negative } \\
(\mathrm{n}=122)\end{array}$ & \\
\hline \multicolumn{4}{|l|}{ MUC5AC } \\
\hline Positive & $17(21)$ & 63 & NS \\
\hline Negative & $30(34)$ & 59 & \\
\hline \multicolumn{4}{|l|}{ MUC6 } \\
\hline Positive & $13(39)$ & 20 & NS \\
\hline Negative & $34(25)$ & 102 & \\
\hline \multicolumn{4}{|l|}{ MUC2 } \\
\hline Positive & $33(55)$ & 27 & $<0.0001$ \\
\hline Negative & $14(13)$ & 95 & \\
\hline \multicolumn{4}{|l|}{ CD10 } \\
\hline Positive & $14(40)$ & 21 & NS \\
\hline Negative & $33(25)$ & 101 & \\
\hline
\end{tabular}

Figures in parentheses are percentages. $\mathrm{p}$ values were calculated by Fisher's exact test. NS = Not significant.

gastric/intestinal phenotypes. Out of the 169 cases examined, each molecule was detected in $80(47 \%)$ cases for MUC5AC, 33 (20\%) cases for MUC6, 60 (36\%) cases for MUC2, and 35 (21\%) cases for CD10. The 169 GC cases were classified into 4 phenotypes: $50(30 \%)$ were the gastric phenotype, 41 (24\%) were the gastric and intestinal mixed phenotype, 42 (25\%) were the intestinal phenotype, and 36 (21\%) were the unclassified phenotype. The positive expression of connexin 30 was significantly more frequent in MUC2-positive cases than in MUC2-negative cases ( $\mathrm{p}<$ 0.0001) (table 2). In immunohistochemical staining, the localized distribution of connexin 30 and MUC2 was partly contiguous (fig. 2c, d). Double immunohistochemical staining, however, did not show a coexpression of connexin 30 with MUC2 in any of the tumor cells (fig. 2e). On the other hand, there was no clear relationship between the expression of connexin 30 and other markers (MUC5AC, MUC6, and CD10) (table 2). Connexin 30 expression occurred more frequently in the intestinal phenotype (48\%) than in other phenotypes (21\%) of GC ( $\mathrm{p}=0.0015)$ (fig. $2 \mathrm{~g}$ ).

\section{Discussion}

Evidence of altered connexin expression in various human malignancies has been accumulating. With regard to the function of connexin in carcinogenesis, there have been several reports of inhibitory effects on the growth of cancer cells [50-53], and transfection and the forced expression of connexin 30 in glioma cell lines has been reported to induce the suppression of tumor growth in vitro $[54,55]$. In the present study, we found that approximately $30 \%$ of GC cases displayed connexin 30 expression, while nonneoplastic gastric mucosa did not express connexin 30. Furthermore, there was a significant inverse association between connexin 30 expression and tumor progression. Once malignant formation is completed, connexin 30 might inhibit GC cell growth and invasion. In addition, we observed a significant inverse association between connexin 30 expression and the presence of metastasis in the regional lymph nodes. Saunders et al. [56], studying the correlation between the metastatic potential of breast cancer cells and gap junctional communication, showed that the disruption of homospecific or heterospecific GJIC contributes to metastatic potential, but mechanisms by which altered connexin expression and GJIC might contribute to this process are unclear and require future studies. Based on our results, we suggest that the aberrant expression of connexin 30 in GC might not play a role in the metastatic efficiency of malignant cells. The present study showed a higher expression of connexin 30 in the differentiated type of GC compared with the undifferentiated type. This may reflect a loss of the ability to produce this protein along with a decrease in histological differentiation in neoplastic cells. Furthermore, in some cases of GC, we observed a cytoplasmic staining pattern of connexin 30. Previous studies reported that connexin 26 translocated from the cell membrane to the cytoplasm in tumor cells $[30,33]$. Furthermore, human connexin 26 and connexin 30 were reported to form functional heteromeric and heterotypic channels [57]. These findings suggest that altered expressions of connexin 30 such as a decrease in functional gap junctions and changed localization of connexin 30 are early events during the development of GC. Although the precise function of cytoplasmic connexin 30 is as yet unclear, one possibility is that the cytoplasmic accumulation of connexin 30 may be a prerequisite for the execution of its role in the cell membrane, contributing to GJIC as needed.

In the present study, the positive expression of connexin 30 showed significant correlation with the positive expression of MUC2. However, there is no previous report showing a direct association between connexin 30 and MUC2. Goblet cells in intestinal metaplasia were positive for MUC2, but scarcely expressed connexin 30 . Yamamoto et al. [58] previously reported that connexin 
32 might be controlled at the transcriptional level via CDX2. Therefore, connexin 30 might also be regulated by CDX2 and displayed the intestinal phenotype of GC. Further studies should be performed in the near future to elucidate a role for CDX2 in the regulation of connexin 30 in GC.

In summary, we revealed that GC with connexin 30 expression demonstrates an intestinal phenotype that is significantly MUC2-positive in expression. Connexin 30 may be a novel differentiation marker mediating the biological behavior of the intestinal phenotype of GC.

\section{Acknowledgements}

We thank Ms. Emiko Hisamoto and Mr. Shinichi Norimura for their excellent technical assistance and advice. This work was carried out with the kind cooperation of the Research Center for Molecular Medicine of the Faculty of Medicine of Hiroshima University. We also thank the Analysis Center of Life Science of Hiroshima University for the use of their facilities. This work was supported in part by grants-in-aid for Cancer Research from the Ministry of Education, Culture, Science, Sports and Technology of Japan and in part by a grant-in-aid for the Third Comprehensive 10-Year Strategy for Cancer Control and for Cancer Research from the Ministry of Health, Labor and Welfare of Japan.

\section{References}

1 Ohgaki H, Matsukura N: Stomach cancer; in Stewart BW, Kleihues P (eds): World Cancer Report. Lyon, IARC Press, 2003, p 197.

-2 Yasui W, Yokozaki H, Fujimoto J, Naka K, Kuniyasu H, Tahara E: Genetic and epigenetic alterations in multistep carcinogenesis of the stomach. J Gastroenterol 2000;35:111115.

3 Ushijima T, Sasako M: Focus on gastric cancer. Cancer Cell 2004;5:121-125.

4 Yasui W, Oue N, Ito R, Kuraoka K, Nakayama H: Search for new biomarkers of gastric cancer through serial analysis of gene expression and its clinical implications. Cancer Sci 2004;95:385-392.

5 Lockhart DJ, Dong H, Byrne MC, et al: Expression monitoring by hybridization to high-density oligonucleotide arrays. Nat Biotechnol 1996;14:1675-1680.

-6 Velculescu VE, Zhang L, Vogelstein B, Kinzler KW: Serial analysis of gene expression. Science 1995;270:484-487.

7 Lauren P: The two histological main types of gastric carcinoma: diffuse and so-called intestinal-type carcinoma. An attempt at a histo-clinical classification. Acta Pathol Microbiol Scand 1965;64:31-49.

-8 Nakamura K, Sugano H, Takagi K: Carcinoma of the stomach in incipient phase: its histogenesis and histological appearances. Gann 1968;59:251-258.

-9 Saito K, Shimoda T: The histogenesis and early invasion of gastric cancer. Acta Pathol Jpn 1986;36:1307-1318.

10 Tahara E: Genetic alterations in human gastrointestinal cancers: the application to molecular diagnosis. Cancer 1995;75:14101417.

11 Tatematsu M, Ichinose M, Miki K, Hasegawa R, Kato T, Ito N: Gastric and intestinal phenotypic expression of human stomach cancers as revealed by pepsinogen immunohistochemistry and mucin histochemistry. Acta Pathol Jpn 1990;40:494-504.
12 Yoshikawa A, Inada Ki K, Yamachika T, Shimizu N, Kaminishi M, Tatematsu M: Phenotypic shift in human differentiated gastric cancers from gastric to intestinal epithelial cell type during disease progression. Gastric Cancer 1998;1:134-141.

13 Tajima Y, Yamazaki K, Nishino N, et al: Gastric and intestinal phenotypic marker expression in gastric carcinomas and recurrence pattern after surgery - immunohistochemical analysis of 213 lesions. Br J Cancer 2004;91:1342-1348.

14 Saito A, Shimoda T, Nakanishi Y, Ochiai A, Toda G: Histologic heterogeneity and mucin phenotypic expression in early gastric cancer. Pathol Int 2001;51:165-171.

15 Kabashima A, Yao T, Sugimachi K, Tsuneyoshi M: Relationship between biologic behavior and phenotypic expression in intramucosal gastric carcinomas. Hum Pathol 2002;33: 80-86.

- 16 Shibata N, Watari J, Fujiya M, Tanno S, Saitoh Y, Kohgo Y: Cell kinetics and genetic instabilities in differentiated type early gastric cancers with different mucin phenotype. Hum Pathol 2003;34:32-40.

$\checkmark 17$ Tsukashita S, Kushima R, Bamba M, Sugihara $\mathrm{H}$, Hattori T: MUC gene expression and histogenesis of adenocarcinoma of the stomach. Int J Cancer 2001;94:166-170.

18 Wakatsuki K, Yamada Y, Narikiyo M, et al: Clinicopathological and prognostic significance of mucin phenotype in gastric cancer. J Surg Oncol 2008;98:124-129.

19 Yuasa Y: Control of gut differentiation and intestinal-type gastric carcinogenesis. Nat Rev Cancer 2003;3:592-600.

-20 Mizoshita T, Tsukamoto T, Nakanishi H, et al: Expression of $\mathrm{Cd} \times 2$ and the phenotype of advanced gastric cancers: relationship with prognosis. J Cancer Res Clin Oncol 2003; 129:727-734.
21 Tsukamoto $\mathrm{T}$, Inada $\mathrm{K}$, Tanaka $\mathrm{H}$, et al: Down-regulation of a gastric transcription factor, Sox2, and ectopic expression of intestinal homeobox genes, $\mathrm{Cdx} 1$ and $\mathrm{Cdx} 2$ : inverse correlation during progression from gastric/intestinal-mixed to complete intestinal metaplasia. J Cancer Res Clin Oncol 2004;130:135-145.

22 Evans WH, Martin PE: Gap junctions: structure and function (Review). Mol Membr Biol 2002;19:121-136.

23 Kumar NM, Gilula NB: The gap junction communication channel. Cell 1996;84:381388.

24 Goodenough DA, Goliger JA, Paul DL: Connexins, connexons, and intercellular communication. Annu Rev Biochem 1996;65: 475-502.

25 Janssen-Timmen U, Traub O, Dermietzel R, Rabes HM, Willecke K: Reduced number of gap junctions in rat hepatocarcinomas detected by monoclonal antibody. Carcinogenesis 1986;7:1475-1482.

26 Mesnil M: Connexins and cancer. Biol Cell 2002;94:493-500.

27 Muramatsu A, Iwai M, Morikawa T, et al: Influence of transfection with connexin 26 gene on malignant potential of human hepatoma cells. Carcinogenesis 2002;23:351-358.

28 Tanaka M, Grossman HB: Connexin 26 gene therapy of human bladder cancer: induction of growth suppression, apoptosis, and synergy with Cisplatin. Hum Gene Ther 2001; 12:2225-2236.

29 Villaret DB, Wang T, Dillon D, et al: Identification of genes overexpressed in head and neck squamous cell carcinoma using a combination of complementary DNA subtraction and microarray analysis. Laryngoscope 2000;110:374-381.

30 Kanczuga-Koda L, Sulkowski S, Koda M, Sulkowska M: Alterations in connexin26 expression during colorectal carcinogenesis. Oncology 2005;68:217-222. 
- 31 Tate AW, Lung T, Radhakrishnan A, Lim SD, Lin X, Edlund M: Changes in gap junctional connexin isoforms during prostate cancer progression. Prostate 2006;66:19-31.

32 Kyo N, Yamamoto H, Takeda Y, et al: Overexpression of connexin 26 in carcinoma of the pancreas. Oncol Rep 2008;19:627-631.

- 33 Jamieson S, Going JJ, D’Arcy R, George WD: Expression of gap junction proteins connexin 26 and connexin 43 in normal human breast and in breast tumours. J Pathol 1998; 184:37-43.

-34 Kanczuga-Koda L, Sulkowski S, Lenczewski $A$, et al: Increased expression of connexins 26 and 43 in lymph node metastases of breast cancer. J Clin Pathol 2006;59:429-433.

- 35 Dahl E, Manthey D, Chen Y, et al: Molecular cloning and functional expression of mouse connexin-30, a gap junction gene highly expressed in adult brain and skin. J Biol Chem 1996;271:17903-17910.

- 36 Lautermann J, Frank HG, Jahnke K, Traub O, Winterhager E: Developmental expression patterns of connexin26 and -30 in the rat cochlea. Dev Genet 1999;25:306-311.

- 37 Nagy JI, Patel D, Ochalski PA, Stelmack GL: Connexin 30 in rodent, cat and human brain: selective expression in gray matter astrocytes, co-localization with connexin 43 at gap junctions and late developmental appearance. Neuroscience 1999;88:447-468.

- 38 Grifa A, Wagner CA, D'Ambrosio L, et al: Mutations in GJB6 cause nonsyndromic autosomal dominant deafness at DFNA3 locus. Nat Genet 1999;23:16-18.

- 39 del Castillo I, Villamar M, Moreno-Pelayo MA, et al: A deletion involving the connexin 30 gene in nonsyndromic hearing impairment. N Engl J Med 2002;346:243-249.
40 Smith FJ, Morley SM, McLean WH: A novel connexin 30 mutation in Clouston syndrome. J Invest Dermatol 2002;118:530-532.

41 Ozawa H, Matsunaga T, Kamiya K, et al: Decreased expression of connexin-30 and aberrant expression of connexin-26 in human head and neck cancer. Anticancer Res 2007; 27:2189-2195.

42 Aasen T, Graham SV, Edward M, Hodgins MB: Reduced expression of multiple gap junction proteins is a feature of cervical dysplasia. Mol Cancer 2005;4:31.

43 Haass NK, Wladykowski E, Kief S, Moll I, Brandner JM: Differential induction of connexins 26 and 30 in skin tumors and their adjacent epidermis. J Histochem Cytochem 2006;54:171-182.

44 Japanese Gastric Cancer Association: Japanese Classification of Gastric Carcinoma, ed 13. Tokyo, Kanehara, 1995.

45 Sobin LH, Wittekind CH (eds): TNM Classification of Malignant Tumors, ed 6. New York, Wiley, 2002, pp 65-68.

46 Gibson UE, Heid CA, Williams PM: A novel method for real time quantitative RT-PCR. Genome Res 1996;6:995-1001.

-47 Kondo T, Oue N, Yoshida K, et al: Expression of POT1 is associated with tumor stage and telomere length in gastric carcinoma. Cancer Res 2004;64:523-529.

48 Oue N, Mitani Y, Aung PP, et al: Expression and localization of Reg IV in human neoplastic and non-neoplastic tissues: Reg IV expression is associated with intestinal and neuroendocrine differentiation in gastric adenocarcinoma. J Pathol 2005;207:185-198.

49 Essenfelder GM, Bruzzone R, Lamartine J, et al: Connexin 30 mutations responsible for hidrotic ectodermal dysplasia cause abnormal hemichannel activity. Hum Mol Genet 2004; 13:1703-1714.

-50 Zhu D, Kidder GM, Caveney S, Naus CC: Growth retardation in glioma cells cocultured with cells overexpressing a gap junction protein. Proc Natl Acad Sci USA 1992; 89:10218-10221.
51 Goldberg GS, Bechberger JF, Tajima Y, et al: Connexin43 suppresses MFG-E8 while inducing contact growth inhibition of glioma cells. Cancer Res 2000;60:6018-6026.

- 52 Seul KH, Kang KY, Lee KS, Kim SH, Beyer EC: Adenoviral delivery of human connexin37 induces endothelial cell death through apoptosis. Biochem Biophys Res Commun 2004;319:1144-1151.

53 Moorby C, Patel M: Dual functions for connexins: $\mathrm{Cx} 43$ regulates growth independently of gap junction formation. Exp Cell Res 2001;271:238-248.

54 Princen F, Robe P, Gros D, et al: Rat gap junction connexin-30 inhibits proliferation of glioma cell lines. Carcinogenesis 2001;22: 507-513.

- 55 Mennecier G, Derangeon M, Coronas V, Herve JC, Mesnil M: Aberrant expression and localization of connexin 43 and connexin 30 in a rat glioma cell line. Mol Carcinog 2008;47:391-401.

56 Saunders MM, Seraj MJ, Li Z, et al: Breast cancer metastatic potential correlates with a breakdown in homospecific and heterospecific gap junctional intercellular communication. Cancer Res 2001;61:1765-1767.

57 Yum SW, Zhang J, Valiunas V, et al: Human connexin 26 and connexin 30 form functional heteromeric and heterotypic channels. Am J Physiol Cell Physiol 2007;293:10321048.

58 Yamamoto T, Kojima T, Murata M, et al: IL1beta regulates expression of $\mathrm{Cx} 32$, occludin, and claudin-2 of rat hepatocytes via distinct signal transduction pathways. Exp Cell Res 2004;299:427-441. 